\title{
Assessment of Cervical Lymph Nodes in Squamous Cell Carcinoma of the Head and Neck
}

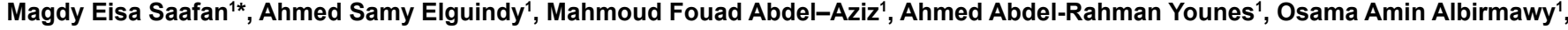 Mahmoud Mandour ${ }^{1}$ and Khalid El-Shafey ${ }^{2}$}

${ }^{1}$ Department of Otolaryngology and Head \& Neck Surgery, Tanta Faculty of Medicine and University Hospitals, Egypt

${ }^{2}$ Departmentof Radiology, Tanta Faculty of Medicine and University Hospitals, Egypt

\begin{abstract}
Background: The most important prognostic factor in squamous cell carcinoma of the head and neck is the presence or absence of clinically involved neck nodes. The presence of metastases in a lymph node is said to reduce the 5 -years survival rate by about $50 \%$. The appropriate diagnosis of the presence of metastatic node is very important for the management of squamous cell carcinoma of the head and neck. The aim of this work is to study the status of cervical lymph nodes in known cases of squamous cell carcinoma in the head and neck and their relation to the primary site.
\end{abstract}

Methods: This study was carried out on 100 consecutive patients with a histologically proven non-cutaneous Head and Neck Squamous Cell Carcinoma (HNSCC). Every patient was subjected to clinical examination for cervical lymph nodes, CT scan on the neck with intravenous contrast and gray scale ultrasound scanning on the neck.

Results: Clinical palpation for cervical lymph nodes had a sensitivity of $71.43 \%$, specificity $75.86 \%$ and accuracy $72.7 \%$. CT scan was better than clinical palpation. The sensitivity for CT was $82.9 \%$, while the specificity was $89.66 \%$ and the accuracy was $84.85 \%$. Ultrasound scanning was found to be the best modality in assessment of metastases in cervical lymph nodes. The sensitivity was $97.1 \%$, the specificity was $93 \%$ and the accuracy was $95.96 \%$. The positive predictive value for Ultrasound scanning was $97.1 \%$ and the negative predictive value was $93 \%$.

Conclusion: CT and ultrasound scanning increase the accuracy of lymph node detection. Although CT is better than clinical palpation, it is also considered inferior to ultrasound scanning in this aspect. Besides, ultrasound scanning is cheaper and with no hazards of radiation exposure.

Keywords: Metastases; Neck; Lymph node; Ultra sonar; Malignancy; $\mathrm{CT}$

\section{Introduction}

Squamous cell carcinoma is the most common malignant tumor in the head and neck region [1]. Lymphatic spread is the most important mechanism in the spread of the head and neck squamous cell carcinomas [2]. The rate of metastases to cervical lymph nodes probably reflects the aggressiveness of the primary tumor. The presence of metastases in a lymph node is said to reduce the 5 -year survival rate by about $50 \%[3]$.

Lymph nodes of the neck have been classified into 7 levels. The spread of carcinoma to these levels is probably predictable according to the site of the primary [4].

The appropriate staging of cervical lymph nodes is very important in the management of any head and neck primary carcinoma. Clinical palpation of cervical lymph nodes has many false negative and false positive results [5,6]. It was said to be existed in $20-40 \%$ of cases $[7,8]$. Computed tomography has improved the accuracy of diagnosis of cervical metastase $[9,10]$. It has disadvantages of being expensive and with hazards of radiation exposure [11,12]. Ultrasound scanning has improved the overall accuracy of diagnosis of cervical metastases [13]. It is a cheap and highly reliable method without hazards of radiation exposure [14,15].

\section{Materials and Methods}

A total of one hundred consecutive patients with a histologically proven non-cutaneous Head and Neck Squamous Cell Carcinoma (HNSCC), were chosen from patients admitted to the Department of Otolaryngology, Head and Neck Syrgery, Tanta University Hospitals, between January 2007 and April 2009.
Each patient was subjected to full history taking, then a complete head and neck examination was performed stressing the site of the previously diagnosed cancer. Nasopharyngeal examination was performed using the 0 and 30 degrees telescopes. In oral cancers, mobility of the tongue, the condition of the floor of the mouth and retromolar trigone was evaluated. For hypopharyngeal and laryngeal cancers, rigid telescopic examination, using the 90 degrees telescope was used. Flexible rhinolaryngoscopy was used especially for patients with a strong gag reflex.

Metastatic workout was performed with whole body CT scan. Patients with distant metastasis, patients with previous radiotherapy and patients having previous neck resections other than skin lesions were excluded from the study.

Palpation of the neck was done thoroughly; first from the back, then from the front of the neck, after exposing the neck down to the level of the clavicle bilaterally to determine the presence or absence of enlarged cervical lymph node. The lymph nodes were assigned using the leveling system adopted by Memorial Sloan Kettering Cancer

${ }^{*}$ Corresponding author: Magdy Eisa Saafan, Department of Otolaryngology and Head \& Neck Surgery, Tanta Faculty of Medicine and University Hospitals, 61 Kafr Esam Street, El Nadi Square, Tanta, Egypt, E-mail: eisamagdy@hotmail.com

Received May 12, 2013; Accepted August 27, 2013; Published September 07, 2013

Citation: Saafan ME, Elguindy AS, Abdel-Aziz MF, Abdel-Rahman Younes A, Albirmawy OA, et al. (2013) Assessment of Cervical Lymph Nodes in Squamous Cell Carcinoma of the Head and Neck. Surgery Curr Res 3: 145. doi:10.4172/21611076.1000145

Copyright: (C) 2013 Saafan ME, et al. This is an open-access article distributed under the terms of the Creative Commons Attribution License, which permits unrestricted use, distribution, and reproduction in any medium, provided the original author and source are credited. 
Center and approved by the American Joint Committee on Cancer (AJCC) $1997[9-11,16]$. The site, size and consistency of the enlarged cervical nodes were reported.

CT examination was performed with a spiral CT Toshiba Xvision/GX scanner (3.5 KHU). Sixty $\mathrm{ml}$ of $76 \%$ intravenous contrast (urographin) were given as a bolus for all patients. Contiguous axial CT sections $(5 / 5-\mathrm{mm})$ were taken from the base of the skull to the level of the clavicles. The lymph nodes were assigned similar levels to that of the clinical examination. We followed the criteria proposed by Sarvanan et al. [17] for CT assessment of the lymph nodes based on the minimal axial diameter of the node as follows: a size of $11 \mathrm{~mm}$ or greater in the transverse plane was considered as a metastatic node. Central hypodensity with peripheral rim enhancement suggestive of necrosis or conglomeration of three or more lymph nodes in the drainage region of the primary tumor were also taken as metastatic lymph nodes.

High resolution ultrasonography on the neck was done by a high resolution real time B-mode (General Electric) " ultrasound machine with a linear transducer of $7.5 \mathrm{MHz}$ frequency. We followed the ratio of long to short axis diameters $(\mathrm{L} / \mathrm{S})$ or $(\mathrm{L} / \mathrm{T})$ as proposed by Steinkamp et al. [18]. This ratio assesses the shape of the lymph node. The nodes were classified according to their $\mathrm{L} / \mathrm{S}$ ratio into 2 classes: $\mathrm{L} / \mathrm{S} \geq 2$ (oval) and $\mathrm{L} / \mathrm{T}<2$ (round). Malignant lymph nodes tend to be round.

Patients with clinical and radiological criteria of malignant metastatic cervical adenopathy were subjected to fine needle aspiration cytology of the suspected nodes, which was ultrasound guided in some patients. Besides, the histopathologic data of specimens removed surgically were analyzed.

Ultimately, clinical, CT and sonographic data as well as histopathologic data from the surgically treated subjects were available as our database. Statistical analysis was performed using the sensitivity, specificity, accuracy, Positive Predictive Value (PPV) and Negative Predictive Value (NPV).

\section{Results}

This study included one hundred consecutive patients with noncutaneous head and neck squamous cell carcinoma (HNSCC), 64 (64\%) of these patients were males and 36 (36\%) were females, ranging in age from 35 to 76 years, with an average of 59 years. One patient died and was missed in the follow up, so the study was completed with 99 patients. Laryngeal carcinoma (32\%) was the commonest cancer in our population, followed by hypopharyngeal carcinoma $(22 \%)$, nasopharyngeal carcinoma (15\%) and oral cancers (15\%).

Results of clinical, CT and ultrasound examination of cervical lymph nodes were also correlated with the cytological findings and the histopathologic results of 25 neck dissections performed in the management plan of some patients of this group. They confirmed the results based on cytologic examination as shown in Tables 1-3 respectively. All nodes with conglomeration or central necrosis (CT criteria): were cytologically positive. The sensitivity and the positive predictive value for conglomeration and central necrosis in CT are $100 \%$. To study the pattern of spread of malignant disease to the neck nodes, we correlated nodal stage, with the primary site and T-stage as shown in Table 4 and Figures 1-3. We found that $85 \%$ of the glottis carcinomas have $\mathrm{N}_{0}$ nodal stage.

\section{Discussion}

Lymphatic spread is the most important mechanism in the spread of head and neck squamous cell carcinomas. The rate of metastases probably reflects the aggressiveness of the primary tumor, and is an important prognostic factor [3].

This work included 100 patients with non-cutaneous head and neck squamous cell carcinoma. Most of our patients were in the $6^{\text {th }}$ decade. Our series showed male predominance. Laryngeal carcinoma followed by hypopharyngeal carcinoma was the most common cancers in our series.

In our series, clinical palpation provided false positive results of about $12.3 \%$ and false negative results of about $47.6 \%$. The sensitivity of clinical palpation in our series was $71.43 \%$; the specificity was $75.86 \%$, while the accuracy was $72 \%$. These figures are in accordance with most reported series for the results of clinical palpation [19].

On the other hand, CT scanning in our series demonstrated a sensitivity of $82.9 \%$, a specificity of $89.66 \%$, and an accuracy of $84.85 \%$. Ultrasound scanning provided the highest sensitivity $(97.1 \%)$, specificity (93\%), and accuracy (95.96\%) for detecting metastatic cervical lymph nodes in our patients.

\begin{tabular}{|l|l|l|l|l|}
\hline & $\begin{array}{l}\text { Cytological } \\
\text { +ve }\end{array}$ & $\begin{array}{l}\text { Cytological } \\
\text {-ve }\end{array}$ & Total & $\quad$ Sensitivity \\
\hline Clinically +ve & 50 & 7 & 57 & Specificity \\
\hline Clinically -ve & 20 & 22 & 42 & Accuracy \\
\hline Total & 70 & 29 & 99 & Positive predictive value \\
\hline
\end{tabular}

Table 1: Correlation between clinical examination and cytological findings.

\begin{tabular}{|l|l|l|l|}
\hline & $\begin{array}{l}\text { Cytological } \\
\text { +ve }\end{array}$ & $\begin{array}{l}\text { Cytological } \\
\text {-ve }\end{array}$ & Total \\
\hline CT +ve & 58 & 3 & 61 \\
\hline CT - ve & 12 & 26 & 38 \\
\hline Total & 70 & 29 & 99 \\
\hline
\end{tabular}

\begin{tabular}{|l|l|}
\hline Sensitivity & $=82.9 \%$ \\
\hline Specificity & $=89.66 \%$ \\
\hline Accuracy & $=84.85 \%$ \\
\hline Positive predictive value & $=95 \%$ \\
\hline Negative predictive value & $=68.4 \%$ \\
\hline
\end{tabular}

Table 2: Correlation between computed tomography (CT) scan and cytological findings.

\begin{tabular}{|c|c|c|c|c|c|}
\hline & \multirow{2}{*}{$\begin{array}{l}\text { Cytological } \\
+v e\end{array}$} & \multirow{2}{*}{$\begin{array}{l}\text { Cytological } \\
\text {-ve }\end{array}$} & \multirow[b]{2}{*}{ Total } & Sensitivity & $=97.1 \%$ \\
\hline & & & & Specificity & $=93 \%$ \\
\hline US +ve & 68 & 2 & 70 & Accuracy & $=95.96 \%$ \\
\hline US -ve & 2 & 27 & 29 & Positive predictive value & $=97.1 \%$ \\
\hline Total & 70 & 29 & 99 & Negative predictive value & $=93 \%$ \\
\hline
\end{tabular}

Table 3: Correlation between ultrasonography (US) scan and cytological findings. 
Citation: Saafan ME, Elguindy AS, Abdel-Aziz MF, Abdel-Rahman Younes A, Albirmawy OA, et al. (2013) Assessment of Cervical Lymph Nodes in Squamous Cell Carcinoma of the Head and Neck. Surgery Curr Res 3: 145. doi:10.4172/2161-1076.1000145

Page 3 of 5

\begin{tabular}{|c|c|c|c|c|}
\hline Primary site & T-Stage & $\mathrm{N}_{0}(\%)$ & $\mathrm{N}_{1}(\%)$ & $\mathrm{N}_{2-3}(\%)$ \\
\hline \multirow[t]{4}{*}{ Larynx $(n=32)$} & $T_{1}$ & 60 & 20 & 20 \\
\hline & $T_{2}$ & 56 & 18 & 26 \\
\hline & $T_{3}$ & 39 & 17 & 44 \\
\hline & $T_{4}$ & 40 & 13 & 47 \\
\hline Hypopharynx & $T_{1}^{*}$ & - & - & - \\
\hline \multirow{3}{*}{$(n=22)$} & $T_{2}$ & 28 & 26 & 46 \\
\hline & $T_{3}$ & 16 & 22 & 62 \\
\hline & $T_{4}$ & 20 & 14 & 66 \\
\hline Nasopharynx & $T_{1}$ & 0 & 25 & 75 \\
\hline \multirow[t]{3}{*}{$(n=15)$} & $T_{2}$ & 25 & 25 & 50 \\
\hline & $T_{3}$ & 25 & - & 75 \\
\hline & $T_{4}$ & 33.3 & - & 66.7 \\
\hline $\begin{array}{l}\text { Lips \& oral } \\
\text { cavity }\end{array}$ & $T_{1}$ & 80 & 20 & 0 \\
\hline \multirow[t]{3}{*}{$(n=15)$} & $T_{2}$ & 66 & 35 & - \\
\hline & $T_{3}$ & 50 & 25 & 25 \\
\hline & $T_{4}$ & 33.3 & 33.3 & 33.4 \\
\hline Oropharynx & $T_{1}$ & 33 & 67 & - \\
\hline \multirow[t]{3}{*}{$(n=13)$} & $T_{2}$ & 25 & 25 & 50 \\
\hline & $T_{3}$ & 33 & - & 67 \\
\hline & $\mathrm{T}_{4}$ & - & 33 & 67 \\
\hline $\begin{array}{l}\text { Paranasal } \\
\text { sinuses }\end{array}$ & $\mathrm{T}_{1}{ }^{*}$ & - & - & - \\
\hline \multirow[t]{3}{*}{$(n=2)$} & $T_{2}$ & - & - & - \\
\hline & $T_{3}$ & 100 & 0 & 0 \\
\hline & $\mathrm{T}_{4}^{*}$ & 0 & 100 & 0 \\
\hline Parotid gland & $\mathrm{T}_{1}{ }^{*}$ & - & - & - \\
\hline \multirow[t]{3}{*}{$(n=13)$} & $\mathbf{T}_{2}^{*}$ & - & - & - \\
\hline & $\mathbf{T}_{3}{ }^{*}$ & - & - & - \\
\hline & $\mathrm{T}_{4}$ & 0 & 0 & 100 \\
\hline
\end{tabular}

Table 4: The probability of cervical metastases $(\mathrm{N})$ related to primary $(\mathrm{T})$ staging in our series.
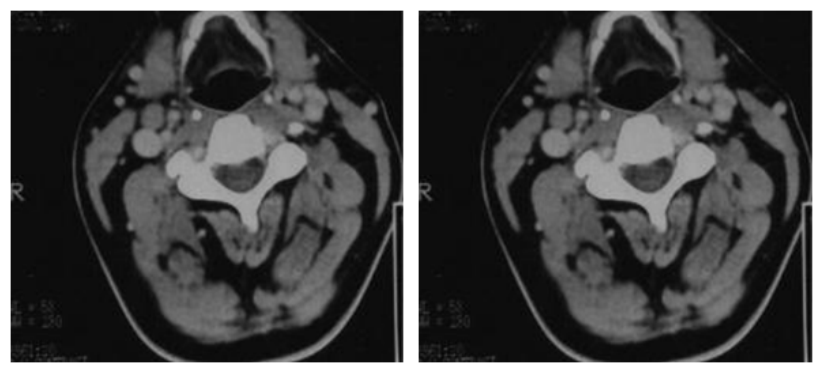

Figure 1a: Two axial CT scans of a patient with left supraglottic primary cancer showing no cervical metastases.

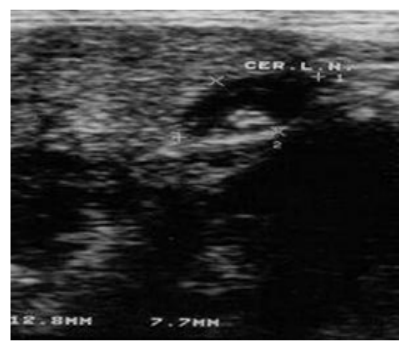

Figure 1b: Ultrasound scan of the same patient showing left level II metastatic lymph node (L/S ratio <2).

The reported incidence of false positive clinical examination of the neck in patients with squamous cell carcinoma of the oral cavity and oropharynx ranged between $10 \%$ to $33 \%$ [16,17]. Clinically occult cervical nodal disease is occurring in $15 \%-40 \%$ of patients undergoing elective neck dissection for cancer arising in this area [16].

Size is the most commonly used CT criterion for differentiating benign from malignant lymph nodes. This is based on the assumption that the larger the node, the greater the probability of metastatic involvement when one is examining a homogenous well-defined node [20].

Geetha et al. [19] reported sensitivity for CT scan $50 \%$ and specificity $100 \%$, while they reported sensitivity $83 \%$ and specificity $50 \%$, for physical examination. In an earlier study by Sönmez [21],

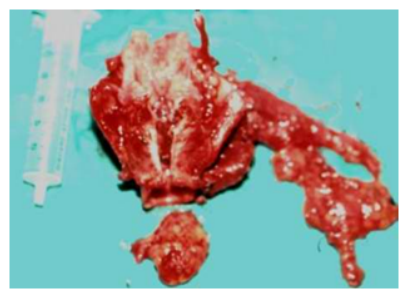

Figure1c: A photo of the operative specimen of the same patient (total laryngectomy with left lateral selective neck dissection).

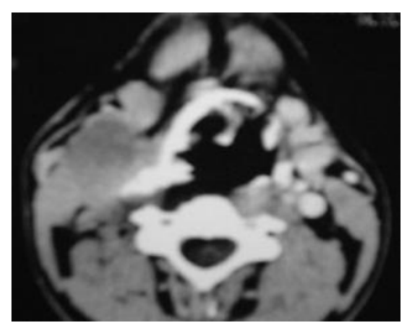

Figure 2a: Axial CT of a patient with right tonsillar carcinoma showing right level II metastatic lymph node.

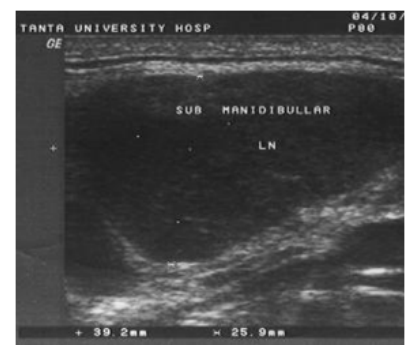

Figure 2b: Ultrasound scanning of the same patient showing metastatic right submandibular (level lb) lymph node (L/S <2).

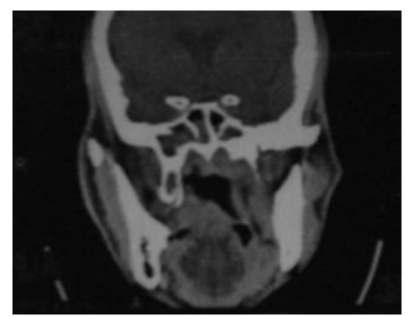

Figure 3a: Coronal CT scan showing left nasopharyngeal carcinoma. 


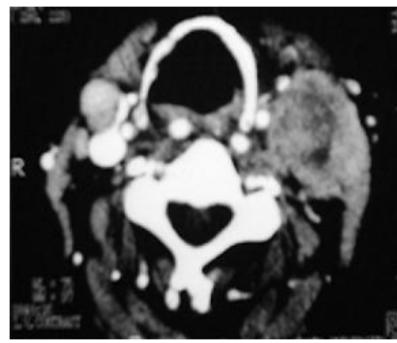

Figure 3b: Axial CT scan of the same patient showing left level II metastatic lymph node with central necrosis.

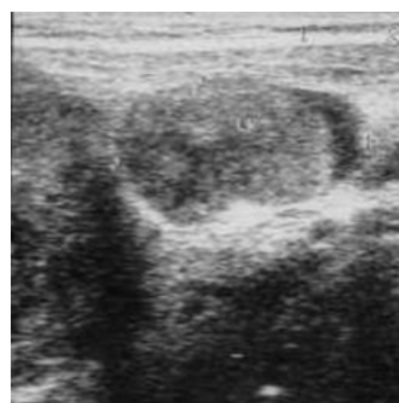

Figure 3c: Ultrasound scan of the previous patient showing the left level II metastatic lymph node (L/S ratio $<2)$.

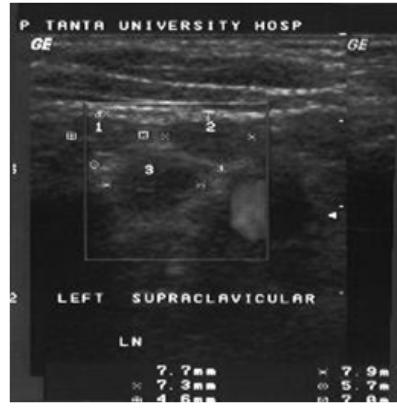

Figure 3d: Ultrasound scan of the previous patient showing left level $\mathrm{V}$ metastatic lymph nodes (L/S ratio <2).

authors have reported sensitivity $95 \%$ and a specificity $47 \%$ for CT scan, while a sensitivity $86 \%$ and a specificity $84 \%$ were reported for physical examination.

Curtin et al. [22] evaluated the sensitivity and specificity of different size criteria for HNSCC metastatic disease and found that a $1-\mathrm{cm}$ size cutoff in the largest axial diameter achieved $88 \%$ sensitivity and $39 \%$ specificity, whereas a $1.5-\mathrm{cm}$ cutoff resulted in $56 \%$ sensitivity and $84 \%$ specificity. More recently, Geetha et al. [19] have used RECIST 1.1 (Response Evaluation Criteria in Solid Tumors) by measuring lymph nodes in the short axis on axial images. They reported that nodes $\geq$ $15 \mathrm{~mm}$ are pathologically enlarged and measurable, and lymph nodes measuring $10-15 \mathrm{~mm}$ in short axis are reportable as pathologic non target sites.

In our series the sensitivity of central nodal necrosis and conglomeration criteria was $100 \%$ with no false positive results. These results go in accordance with the observations made by Van den Brekel [23] and Sarvanan et al. [17]. Sarvanan et al. [17] suggested that the presence of central necrosis was the most specific sign of metastatic lymphadenopathy. They reported $100 \%$ sensitivity and specificity for central nodal necrosis criteria.

Ultrasonography is an alternative imaging modality which is considered an accurate and reliable method of evaluating neck metastases. The staging of the carcinoma of the head and neck is an important goal of head and neck imaging using ultrasonography [5]. Griffith et al. [24] showed that the addition of neck ultrasonography to staging by clinical and CT criteria resulted in a change in TNM staging in $22 \%$ of patients in their study. They suggested that more accurate preoperative staging with neck ultrasonography allows a more consistent selection of patients for different treatment protocols.

In our series, we have chosen the criterion of L/S (longitudinal/ short axis) ratio for differentiation between benign and malignant nodes. Kim et al. [25] found that there was no significant difference between benign and malignant nodes in terms of their largest diameter, but, there was marked difference in terms of their $\mathrm{L} / \mathrm{S}(\mathrm{L} / \mathrm{T})$ ratio (or shape) which can be assessed without limitations only with ultrasound scanning. Since metastasis causes lymph node enlargement by malignant cell proliferation it alters the normal ovoid shape of the lymph node to a more spherical form, while benign processes tend to maintain the oval shape of the lymph node, in which enlargement occurs by benign lymphoid cell proliferation. The tendency of benign nodes to be "oval" $(\mathrm{L} / \mathrm{S}>2)$ and malignant nodes to be "round" $(\mathrm{L} / \mathrm{S}<2)$ has also been reported by other observers $[5,19]$.

Our results agree with the results of most previous studies, which have taken the L/S ratio as criteria of differentiation between benign and malignant lymphadenopathy. In our series, we have reported a sensitivity of $71.43 \%$ and a specificity of $75.86 \%$ for palpation of lymph nodes. A sensitivity of $82.9 \%$ and a specificity of $89.66 \%$ for CT scanning and a sensitivity of $97.1 \%$ and a specificity of $93 \%$ for ultrasound scanning. Steinkamp et al. [18] reported $95 \%$ sensitivity of the $\mathrm{L} / \mathrm{S}$ ratio as well as a specificity of $95 \%$ compared with $37 \%$ for the long axis method and $86 \%$ for the transverse diameter method. They noted the decrease of false positive results from $63 \%$ to $5 \%$ using the L/S ratio. Sarvanan et al. [17] have showed similar sensitivity (94.44\%) and higher specificity (100\%) than that reported by Steinkamp et al. [18].

In 1993 , John et al. [26] reported sensitivity of $62 \%$, specificity of $80 \%$ and accuracy of $81 \%$ for palpation in the upper neck, while reported sensitivity of $44 \%$, specificity of $67 \%$ and accuracy of $67 \%$ for ultrasonography in the upper neck. They reported sensitivity and specificity of $100 \%$ for palpation and ultrasonography in the midneck with 95\% accuracy for both methods. They reported that in the posterior triangle, sensitivity for palpation was $38 \%$ and for ultrasonography $60 \%$. The specificity for palpation was $64 \%$ and for ultrasonography $85 \%$; and accuracy was $57 \%$ for palpation and $67 \%$ for ultrasonography. In a more recent study, Sureshkannan et al. [5] presented a sensitivity of $85.7 \%$ and a specificity of $90 \%$ for ultrasound scanning, while the clinical examination presented sensitivity $68.7 \%$ and specificity $87.5 \%$. Geetha et al. [19] reported the sensitivity in detection of cervical lymph nodes to be $83 \%$ for palpation and $100 \%$ for ultrasound scanning.

Ultrasound scanning has an advantage of being a simple noninvasive maneuver with no hazards of exposure to radiation. Moreover, ultra-sonography can detect lymphadenopathy in presence of severe postoperative scarring or post radiotherapy thickening of the soft tissues of the neck [16]. Ultrasonography appears to be the best modality for assessing carotid artery invasion. Ultrasonography can be considered a valuable diagnostic measurement for cancer tongue. By providing a three dimensional view of the tumor, it is more accurate 
than palpation in detecting spread of tumor across the midline, to the base of the tongue and floor of the mouth. The tumor is predominately hypoechoic. It is difficult to differentiate fibrosis from tumors and also to detect very superficial lesions.

Other study suggestes that ultrasound combined with ultrasound guided fine needle aspiration cytology is a reliable, safe and simple method in staging head and neck malignancies and may be useful in the follow up of the patients. Van den Brekel et al. [27] has reported a specificity of $100 \%$ for ultrasound guided fine needle aspiration cytology. They Showed that sonography guided fine needle aspiration cytology often ensures detection of neck recurrences at an early stage.

\section{Conclusion}

From this work, it is concluded that we should not rely solely on clinical examination; other diagnostic modalities should be considered. $\mathrm{CT}$ and ultrasound scanning increase the accuracy of lymph node detection. Although CT is better than clinical palpation, it is also considered inferior to ultrasound scanning in this aspect. Besides, ultrasound scanning is cheaper and with no hazards of radiation exposure.

\section{References}

1. Rothenberg SM, Ellisen LW (2012) The molecular pathogenesis of head and neck squamous cell carcinoma. J Clin Invest 122: 1951-1957.

2. Mokhtari S (2012) Mechanisms of cyst formation in metastatic lymph nodes of head and neck squamous cell carcinoma. Diagn Pathol 7: 6.

3. Hoang JK, Vanka J, Ludwig BJ, Glastonbury CM (2013) Evaluation of cervical lymph nodes in head and neck cancer with CT and MRI: tips, traps, and a systematic approach. AJR Am J Roentgenol 200: W17-25.

4. Ferlito A, Robbins KT, Shah JP, Medina JE, Silver CE, et al. (2011) Proposal for a rational classification of neck dissections. Head Neck 33: 445-450.

5. Sureshkannan P, Vijayprabhu, John R (2011) Role of ultrasound in detection of metastatic neck nodes in patients with oral cancer. Indian J Dent Res 22: 419-423.

6. Anand N, Chaudhary N, Mittal MK, Prasad R (2007) Comparison of the efficacy of clinical examination, ultrasound neck and computed tomography in detection and staging of cervical lymph node metastasis in head and neck cancers. Indian J Otolaryngol Head Neck Surg 59: 19-23.

7. Castelijns JA, van den Brekel MW (2001) Detection of lymph node metastases in the neck: radiologic criteria. AJNR Am J Neuroradiol 22: 3-4.

8. Yuasa K, Kawazu T, Kunitake N, Uehara S, Omagari J, et al. (2000) Sonography for the detection of cervical lymph node metastases among patients with tongue cancer: criteria for early detection and assessment of follow-up examination intervals. AJNR Am J Neuroradiol 21: 1127-1132.

9. Saindane AM (2013) Pitfalls in the staging of cervical lymph node metastasis. Neuroimaging Clin N Am 23: 147-166.

10. Liao LJ, Lo WC, Hsu WL, Wang CT, Lai MS (2012) Detection of cervical lymph node metastasis in head and neck cancer patients with clinically N0 neck-a meta-analysis comparing different imaging modalities. BMC Cancer 12: 236.

11. Gor DM, Langer JE, Loevner LA (2006) Imaging of cervical lymph nodes in head and neck cancer: the basics. Radiol Clin North Am 44: 101-110, viii.

12. de Bree R, Castelijns JA, Hoekstra OS, Leemans CR (2009) Advances in imaging in the work-up of head and neck cancer patients. Oral Oncol 45: 930935.
13. Haberal I, Celik H, Gocmen $H$, Akmansu $H$, Yörük M, et al. (2004) Which is important in the evaluation of metastatic lymph nodes in head and neck cancer: palpation, ultrasonography, or computed tomography? Otolaryngol Head Neck Surg 130: 197-201.

14. Richards PS, Peacock TE (2007) The role of ultrasound in the detection of cervical lymph node metastases in clinically NO squamous cell carcinoma of the head and neck. Cancer Imaging 7: 167-178.

15. Wensing BM, Merkx MA, De Wilde PC, Marres HA, Van den Hoogen FJ (2010) Assessment of preoperative ultrasonography of the neck and elective neck dissection in patients with oral squamous cell carcinoma. Oral Oncol 46: 87-91.

16. Sundar R, Rajesh P (2007) Evaluation of clinical assessment, Ultrasonography and CT for detecting cervical lymph node metastasis in oral CA. J Maxillofac Oral Surg 6: 70-73

17. Sarvanan K, Bapuraj JR, Sharma SC, Radotra BD, Khandelwal N, et al. (2002) Computed tomography and ultrasonographic evaluation of metastatic cervical lymph nodes with surgicoclinicopathologic correlation. J Laryngol Otol 116 194-199.

18. Steinkamp HJ, Cornehl M, Hosten N, Pegios W, Vogl T, et al. (1995) Cervical lymphadenopathy: ratio of long- to short-axis diameter as a predictor of malignancy. Br J Radiol 68: 266-270.

19. Geetha NT, Hallur N, Goudar G, Sikkerimath BC, Gudi SS (2010) Cervica lymph node metastasis in oral squamous carcinoma preoperative assessment and histopathology after neck dissection. J Maxillofac Oral Surg 9: 42-47.

20. Schwartz LH, Bogaerts J, Ford R, Shankar L, Therasse P, et al. (2009) Evaluation of lymph nodes with RECIST 1.1. Eur J Cancer 45: 261-267.

21. Sönmez A, Oztürk N, Ersoy B, Bayramiçli M, Celebiler O, et al. (2008) Computed tomography in the management of cervical lymph node pathology. Plast Reconstr Aesthet Surg 61: 61-64.

22. Curtin HD, Ishwaran H, Mancuso AA, Dalley RW, Caudry DJ, et al. (1998) Comparison of CT and MR imaging in staging of neck metastases. Radiology 207: 123-130.

23. van den Brekel MW, Castelijns JA, Snow GB (1998) Diagnostic evaluation of the neck. Otolaryngol Clin North Am 31: 601-620.

24. Griffith JF, Chan AC, Ahuja AT, Leung SF, Chow LT, et al. (2000) Neck ultrasound in staging squamous oesophageal carcinoma - a high yield technique. Clin Radiol 55: 696-701.

25. Kim HC, Yoon DY, Chang SK, Han H, Oh SJ, et al. (2010) Small atypical cervical nodes detected on sonography in patients with squamous cell carcinoma of the head and neck: probability of metastasis. J Ultrasound Med 29: 531-537.

26. John DG, Anaes FC, Williams SR, Ahuja A, Evans R, et al. (1993) Palpation compared with ultrasound in the assessment of malignant cervical lymph nodes. J Laryngol Otol 107: 821-823.

27. van den Brekel MW, Reitsma LC, Quak JJ, Smeele LE, van der Linden JC et al. (1999) Sonographically guided aspiration cytology of neck nodes for selection of treatment and follow-up in patients with NO head and neck cancer. AJNR Am J Neuroradiol 20: 1727-1731. 